\title{
The Paradigms of Accounting and Financial Reporting
}

\author{
Igor J. Yaremko \\ Institute of Economics and Management \\ Lviv Polytechnic National University, Ukraine \\ i.yaremko@i.ua \\ Lubomyr M. Pylypenko \\ Institute of Economics and Management \\ Lviv Polytechnic National University, Ukraine \\ liubomyr.m.pylypenko@lpmu.ua \\ Olena I. Tyvonchuk \\ Institute of Economics and Management \\ Lviv Polytechnic National University, Ukraine \\ olenatywonchuk@gmail.com
}

\begin{abstract}
Purpose - The aim of the article is to substantiate the prerequisites for the development of a new paradigm of accounting and financial reporting of companies in postindustrial economy.

Design/Methodology/Approach - The study is based on the analysis of the existing approaches to the formation of accounting and financial reporting paradigm. For the new paradigm development the concept of intellectual capital maintenance and theoretical provisions of physical economy were applied. Originality/Value - On the basis of the research, a number of anomalies and crises of existing accounting paradigm have been defined. In order to eliminate them, the main requirements for the new paradigm have been defined, in particular: explicit positioning of public importance of general purpose financial reporting (institutional context); complete representation of company's intellectual potential by the system of accounting and financial reporting; consideration of social, environmental and ethical aspects of companies operation as important criteria of their overall effectiveness; consideration of dynamics of an economic development factor in the approaches to accounting objects valuation.
\end{abstract}

Keywords - accounting, financial reporting, paradigm, concept of capital maintenance, physical economy.

\section{Introduction}

Nowadays the crises, stagnation and recession have taken systematic forms on the level of both macroeconomic systems and separate business entities. The most evident such phenomena are in corporate sector. Inadequate information support of administrative

The Paradigms of Accounting and Financial Reporting 
IJSR 5

and regulatory bodies, market institutions, rating agencies is particularly important among the many factors of unpredictability and crisis situations in the economy.

Financial reporting is traditionally considered as a main formalized information tool for the disclosure of business performance and financial position of entities. However, used in modern practice format of general purpose financial reporting of economic agents is not able to meet the information needs and demands of users, particularly regarding the assessment of potential for long-term development of corporations. The low level of reporting format adequacy with business conditions in the post-industrial economy is caused primarily by the theoretical and methodological limitations of representing key factors that yield economic benefits. And among them intangible (information and intellectual) factors play a crucial role.

The imperfection of accounting and reporting methodology, its inability to solve the current problems of information support of post-industrial companies' stakeholders objectively necessitates the development of new accounting paradigm. The urgency of the problem is confirmed by the significant interest in this issue on the part of scientists and practitioners in various financial and economic spheres.

\section{Analysis of existing accounting paradigms and preconditions for a new paradigm development}

The detailed study of scientific approaches to accounting paradigms has been held by Legenchuk (2012). The main emphasis in his researches is done on the analysis of the correspondence of accounting paradigms, outlined and classified by different scientists, with the fundamental basis of Kuhn's concepts of paradigm (Kuhn, 1962). The key preconditions for a new paradigm, according to his theory, are the emergence of anomalies - "new phenomena that do not fit the traditional paradigm", crisis - "the dilution of paradigm and the emergence of its different versions", revolution or paradigm shift - "rejection of the old and the emergence of a new paradigm" (Legenchuk, 2012). The first two preconditions anomalies and crises - have long been evident in accounting and reporting methodology. In particular, the anomalies of current, but outdated accounting paradigm could include:

- $\quad$ significant difference between the book and the market value of companies;

- enhancing (prevalent) role of intellectual and informational factors in value creation and efficient operation of business entities. With existing accounting methodology it is impossible to introduce these factors in a formalized way in accounting system, disclose in reporting and, consequently, provide users with relevant and objective information;

- the urgent necessity of account for the mutual influences of entities' results of operation and environment, social and economic spheres, especially in the context of globalization of economic processes;

- significant expansion of stakeholders, groups of economic impact, interested in the activities of the companies, which information needs the corporate reporting is aimed to meet. With the implementation of a funded pension system the range of socially interested persons must be considered much broader than traditionally seen.

These and other anomalies have led to many scientific crises in accounting, causing, in particular, the development of alternative, evaluative and analytical tools of 
representation of companies' performance and economic potential, including Intellectual Capital Report, Cost Management Report, components of non-financial reporting into the structure of corporate or management reporting, as well as the development of concept of integrated reporting, etc. (Figure 1). The dilution of paradigm and the emergence of its different versions are observed not just in accounting in general, but also concerning the methodological approaches to reflecting its individual objects capital, income, intangible assets, good will and others.

Despite actuality and considerable interest to the topic of a new accounting and reporting paradigm, the researches of Legenchuk (2012) have shown that most scientists only emphasize the necessity of its development or distinguish specific conditions and criteria for its formation. The attempts of building a new accounting paradigm have been done by Zhuk (2010), Malyuga (2005), Lev (2000), Chaikovska (2007) (Table 1).

The approach of Lev, who bases the configuration of a new paradigm on improved U.S. GAAP, is quite polemical not because of the imperfection of these principles or because of the controversy over their matching with the other systems of standardization, such as IFRS. The controversy reveals mostly as a consequence of the approach, which implies dynamic system of standardization as a base of theoretical construction (which is the paradigm). Such a system constantly changes and is just a set of principles and rules that are not always theoretically and methodologically linked.

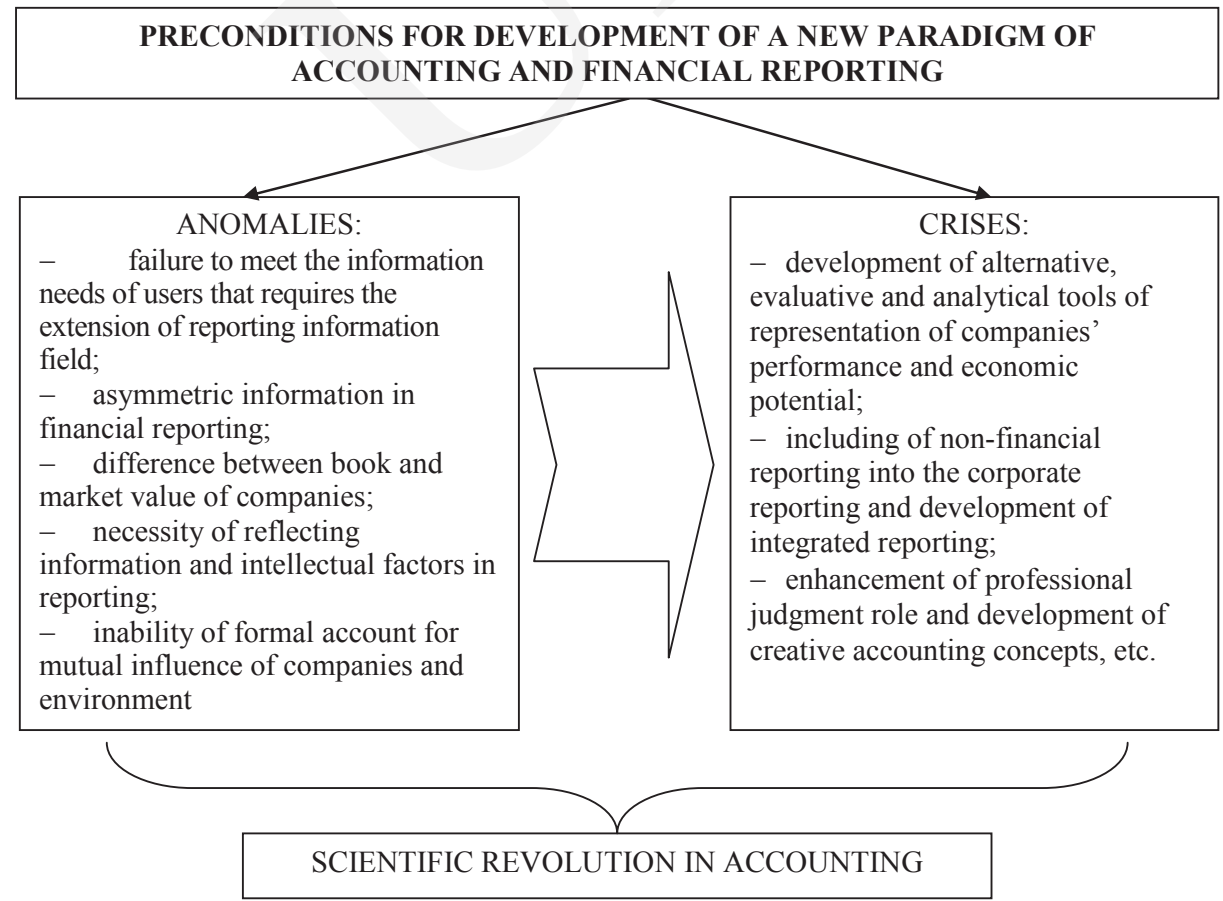

Figure 1.

The factors of new paradigm of accounting and financial reporting development

Source: Elaborated by the authors on the basis of Legenchuk (2012). 


\section{IJSR}

5

Table 1.

New Accounting

Paradigms

The author and the name of a paradigm
Lev (2000) - The economic asset-based
accounting system
Chaikovska (2007), Zhuk (2010) - Institutional
accounting paradigm

Conceptual focus of a paradigm

The paradigm is based on a business model of a company that operates in knowledge-driven economy. It covers three components: improved GAAP US, financial and economic capital and nonfinancial capital

Accounting paradigm is formulated from the perspective of the institutional concept of accounting. This concept implies the development of accounting system taking into account the interaction of basic socioeconomic incentive for users of financial information and accountants, accounting regulations, and forms of organization and self-organization of accounting

The paradigm defines the objective of accounting as providing information to interested users, the main task - as reallocation of resources in the economic system. Involves consideration of new accounting objects intellectual capital, natural resource potential and information.

In the opinion of Legenchuk, the new paradigm development, taking into account Kuhn's scientific concepts of a paradigm, should be characterized by noncumulativity (complete or partial incompatibility between old and new paradigms) and incomparability (impossibility to prove logically the greater level of objectivity (truth) of a new or old paradigm by their supporters). While on the other hand, in his work there are also other arguments, including these of Voynarenko, that "the emergence of a new accounting paradigm does not mean the complete shift in the system of views. (...) the new accounting paradigm (...) should consider new trends (...) [and] absorb the positive elements of the previous paradigm" (Legenchuk, 2012). Malyuga also states that the "new paradigm has to consider new technologies and new objects peculiar to the current state of societal development. It should not lose its dual character as the highest expression of dialectical method of accounting" (Malyuga, 2005). Thus, the new accounting paradigm could not be characterized by complete noncumulativity regarding the old paradigm.

Given the defined anomalies and crises of an existing paradigm of accounting and financial reporting it is possible to distinguish the main criteria that should be met by a new paradigm:

- the social significance of accounting and financial reporting (institutional context). The old paradigm is focused mainly on meeting information requests of investors and lenders that is directly stated in the Conceptual Framework for Financial Reporting - "the objective of general purpose financial reporting is to provide financial information about the reporting entity that is useful to existing and potential investors, lenders and other creditors in making decisions about providing resources to the entity" (Conceptual Framework for Financial Reporting, 2010). Then, the new paradigm should equally consider the interests of all stakeholders of the company as institutional subjects. Social importance of accounting determines the focusing of accounting and reporting methodologies development from the format of reporting, defined by information needs of social groups of economic impact, to the accounting methods that can ensure relevant format of reporting; 
- full representation of the company's intellectual potential by the system of accounting and financial reporting;

- recognition of social, environmental, and ethical aspects of companies' operation as meaningful criteria of their performance;

- taking into account the effect of dynamics of economic development in the approaches to accounting objects evaluation. On the one hand, this requires deviation from historical cost principle (for example, in evaluation of non-current assets the accrual of depreciation loses its meaning because of the rapid obsolescence), but on the other, the fair value, focused on market, loses its objectivity under the influence of the volatility.

Matching to these criteria accounting paradigm in the context is very close to the Malyuga's paradigm "Dual Information Dynamics", but has some significant differences, in particular:

- the main socio-economic function of accounting, in our opinion, is the resource allocation not only in the economic system, but also over the time (between human generations). The intensive today's consumption could leave the future generations without any resources. In this regard this does not just imply expensive for the modern society precious metals and gemstones, hydrocarbons and other energy, the reserves of which have been nearly depleted, but also the fundamental resources, without which the life is impossible - water, air, humus soil, etc.;

- the purpose of the balance sheet is to reflect objectively and representatively the financial position of the company, not only its real market value;

- among the new accounting objects it is appropriate to distinguish intellectual capital rather than intellectual potential (the concept of its reflection in accounting and reporting is disclosed below); instead of natural resources potential - the social and environmental factors and companies' performance should be distinguished and so on.

The inability of existing accounting methodology to recognize and measure new objects because of their diversity and dynamics of development caused that some scientists and experts insist on the advisability of applying principles of creative accounting (Legenchuk, 2012). Creative accounting implies the increasing role of accounting judgments, extension of freedom and creativity, since the current conditions (reduction in the time lags) require the disclosure of hidden, unseen before, factors determining the development of entity's external environment. However, such prospects of accounting development should be treated with caution because the loss of its formal structure significantly unbalances the quality level of accounting-based formalized information. Eventually, it is the creativity in accounting that has enabled the manipulations in financial reporting and, therefore, in opinions and decisions of investors and shareholders, which have led to corporate financial crises at the end of the 1990s - at the beginning of the 2000s (scandals with the companies «Enron», «Parmalat» and others are disclosed in detail in the media).

Overall, this points to the fact that the methodological approaches to the development of accounting, new accounting objects representation in financial reporting within the new paradigm framework require further thorough researches and studies.
The Paradigms of Accounting and Financial Reporting 
IJSR 5

\section{Conceptual approach to intellectual potential representation in accounting and reporting}

The problems of theory and methodology of accounting for components of companies' intellectual potential are the subject of study of many modern scientists, such as Brooking, Edvinsson, Lev, Malone, Stewart and others. A considerable share of the proposals based on the results of their researches is rational, that is, can be directly used for improving the methods of accounting for components of intellectual potential of the company (primarily intangible (intellectual) assets). However, the issues related to overall adaptability of accounting and intellectual potential representation in financial reporting remain unresolved and require considerable development of both theoretical and methodological approaches to their solution.

The problems of intellectual potential components reflection in accounting are caused by inconsistency between accounting methodology and modern business practices, since the basic principles of accounting for intangible assets remained virtually unchanged for over a century (in fact, since the publication of static accounting theory). Inherent in this theory principle of objectification implies the recognition of purchased intangible assets only, while self-created intellectual objects are not recognized as assets at all. The essence of this principle is mostly consistent with the modern accounting methodology, which, on the one hand, creates significant obstacles to the recognition of company intellectual potential and its representation in financial reporting, but on the other protects reporting from generation of fictitious ("toxic") assets along with real.

The main reason for the gap between the market and book value of public companies is undervaluation of their intellectual potential. Significant amounts of such gaps indicate excessive "rigidity" of the principle of objectification as a mechanism of protection against fictitious or toxic assets. Many experts and scientists believe that it is extremely important and necessary to find a way out of this methodological impasse by development and formulation of relevant prerequisites (principles, criteria, etc.) for the recognition of self-created intellectual products as company's assets.

The conceptual preconditions for the development of accounting for intellectual potential methodology should be based primarily on determination of its nature as an accounting object and classification. In scientific studies, scientists use different terms to describe intellectual potential - intangible assets, intellectual assets, intellectual resources, intellectual capital and many others. Inconsistency of categorical system not only leads to confusion but also causes additional methodological problems. In particular, Legenchuk outlines a number of "misconceptions" and unresolved issues of accounting and control of intellectual capital, among which he emphasizes the controversy regarding the use of the term "intellectual assets" and the fallacy of intellectual capital attribution to the liabilities side of the balance-sheet (Legenchuk, 2010). On the other hand, it might seem illogical to use the term "capital" in the names of accounting objects that belong to the assets side of the balance sheet, since among the components of intellectual capital, the following items could be singled out: trademarks, copyrights and other intellectual property rights, patents, software and other technological developments, knowledge, know-how, as well as such components as client, human and organizational capitals. The combination of these components creates intellectual "mess", for which it is 
difficult (or impossible) to pick up a single, relevant to the accounting object title. From an accounting point of view, these components are of different nature and economic substance. Therefore, it is appropriate to distinguish intellectual assets and intellectual capital as separate accounting objects.

The term "intellectual assets" should imply the assets, which have no material form and are the result (product) of human intellectual activity. These include trademarks, copyrights, know-how, patents, software, technological developments and so on. Intellectual capital refers to as the sources of intellectual assets; it is a substance with such defining properties of capital as reproduction, multiplication or reduction. Intellectual capital, the same as the other types of company capital, is capable of generating economic benefits not directly but due to the formed intellectual assets.

Thus, there is an intrinsic link between intellectual capital and intellectual assets of the company, since the latter are the result of intellectual capital's productive energy. But the intellectual capital of the company is not the only source of its intellectual assets. Intellectual assets may be acquired from the other business entities (according to the current accounting methodology such objects are recognized and reflected on the balance sheet as intangible assets), i.e. to be formed from the other types of capital equity, retained earnings or debt capital.

In terms of representation on the balance sheet it seems reasonable to reflect information on intellectual assets at the assets side of the balance sheet and intellectual capital respectively at the liabilities side of the balance sheet. However, a number of customary methodological provisions of intrinsic fundamental nature create obstacles to the accounting recognition of intellectual assets and intellectual capital. Along with this, the extremely high level of urgency of studied problems (primarily completeness of intellectual potential representation in financial reporting) causes the public requirements for their solutions even beyond the existing imperative methodology or through its modernization.

The traditional monetary approach to the formation of the liabilities side of the balance sheet as a combination of the sources of its assets' financing, at first glance, does not allow to reflect intellectual capital. Indeed, the creation of intellectual assets is financed by the other types of capital through wages, material and other costs. However, the real value of intellectual assets (in terms of their usefulness) is significantly different from the cost of their creation, as confirmed by the goodwill emergence. So there is another, additional to the sources of financing, substance of value creation and intellectual assets formation - intellectual capital that substantiates the relevance and necessity of its representation in liabilities side of the balance sheet.

Unlike intellectual assets, intellectual capital cannot be purchased, sold or transferred to another entity. With other types of capital - equity, retained earnings or debt capital intellectual capital has both similarities and differences. These common characteristics might include already mentioned properties of reproduction, multiplication or reduction, as well as the existence of productive energy of intellectual capital. However, it cannot be paid off, distributed or withdrawn, as it is inseparable from the company. Yaremko calls such capital "ideal" and states that this is "a true owner's equity of the company that can exist only along with it, cannot be withdrawn as, for example, a part of share capital", and in terms of traditional accounting intellectual capital is "an absolute capital of economic unit" (Yaremko, 2002).
The Paradigms of Accounting and Financial Reporting 
IJSR 5

In today's dynamic economic environment the development of the company is impossible without innovation (as was proved by the famous scientist Joseph Schumpeter at the beginning of the twentieth century (Schumpeter, 1911)) and innovations are directly related to intellectual assets (as a result of their use or implementation). Given the fact that intellectual assets can be internally generated (as a result of the productive power of intellectual capital) or purchased, innovation can be provided by intellectual or other types of company capital. In the absence of intellectual capital, intellectual assets can only be purchased, and, therefore, innovative development of the company will require constant expenditure of equity, profit or debt capital. Thus, assuming the same efficiency of production and use of intellectual assets, we can conclude that the company without intellectual capital is in much worse economic situation than the company with such capital. Therefore, the intellectual capital is an essential factor of the efficient operation of the business that again actualizes the need for its representation in accounting and reporting for information support of managerial decisions making of the various company stakeholders.

Accounting methodology identifies the following key criteria for the recognition of assets, which, obviously, should be also applied for the recognition of intellectual assets:

- the control by the entity;

- it is probable that the expected future economic benefits that are attributable to the asset will flow to the entity;

- the cost of the asset can be measured reliably.

Provision of company control over the intellectual objects as the possibility of decisive influence on them in order to obtain benefits from their use is determined by the technical and legal aspects. The lack of physical substance of intellectual assets creates the opportunities for their multiplication and dissemination among other entities. However, the amount of the economic benefits from intellectual assets' usage depends largely on their uniqueness that is lost as a result of massive uncontrolled spread of such assets. On the other hand, persons involved in the creation of intellectual objects may be eligible to participate in the ownership of such objects, which also complicates the control over them by the company.

The other two criteria for intellectual assets recognition are closely linked: considering the inconsistency of cost approach to valuation of intellectual objects (especially internally generated) with market trends, their valuation should be based on the expected economic benefits from the use of such assets. However, the dynamic development of economic environment and the rapid obsolescence of all types of technologies (including management technologies) make any forecasts (especially long term) extremely subjective which causes deep methodological problem of evaluation of intellectual assets and creates a significant obstacle to their recognition in accounting.

The intellectual potential of modern company is a key factor not only of generating economic benefits, but also of sustainable operation in the economy of crisis character. In turn, the potential economic benefits must become the basis for measuring value of intellectual potential (both assets and capital). However, the following accounting methodological question arises: what part of received economic benefits should be recognized as a profit of the company, and which - assigned to the maintenance and recovery of intellectual potential. The answer to the question about distribution of profitability and intellectual potential maintenance should be based on the concept of 
intellectual capital maintenance. Applying scientific analog method, the content of this concept for knowledge-based economy can be formulated this way: a profit is only generated when the productive energy of intellectual potential (or the resources or funds for its reproduction) at the end of the period exceeds the productive energy of intellectual potential at the beginning of the period excluding any payments to owners and contributions from owners during this period. Thus, the development of fundamental basis of accounting model with a view to eliminating its current flaws, in our opinion, should be implemented towards reconciliation or compromise between at least three concepts of capital maintenance - financial, physical and intellectual capital; the choice of determining concept may significantly depend on the profile of the company.

\section{Conceptual approach to representation of social and environmental factors and companies performance in accounting and reporting}

The model of socio-economic relations, required currently by a large majority of society, can be considered as human-centric. This is a model focused on the health and well-being of each person in particular and humanity in its various organizational forms in general. Some scientists and experts call such a model of social and economic relations 'sociallyoriented economy'. However, consideration of the vital activity safety in the context of both current and future generations without taking into account the trends of development and influences of environment is meaningless. Therefore, the conceptual framework of socially-oriented economy is complemented by environmental criteria that lead to the formation of Socio-Ecological Market Economy (SEME).

After all, the "eco annex" to the model of socio-economic relations resulted from the real environmental problems on a global scale - global warming, resource depletion, pollution and many others. The solution of these problems is impossible without a radical change in the methods of economic activity, but, at the same time, requires substantial financial allocations. Not addressing these issues might undoubtedly lead to the global catastrophe or apocalypse.

The SEME model is underpinned by the concepts of post-industrial society and sustainable development. An important contribution to the development of fundamental basis of sustainable development concept has been made by Ukrainian scientists, representatives of national school of physical economy, in particular Podolinsky, Vernadsky and Rudenko.

The physical economy, unlike the political, considers the real economy, leaving aside financial measures of economic performance. It studies economy as physical processes - as living organisms of a special sort. The work Human Labor and Its Relation to the Distribution of Energy, written by the founder of a Ukrainian physical economy school - Podolinsky, pioneered a thermodynamic approach to economic processes. The scientist showed that "accumulation of energy on the earth's surface is possible due to informed (conscious) and useful work" (Podolinsky, 1881). Rudenko, who can be regarded as the follower of Podolinsky in the economic area of his scientific research, in his works Progress Energy and Gnosis and Modernity (Universe Architecture) (1999,
The Paradigms of Accounting and Financial

Reporting 
IJSR 5
2005) developed the doctrine of Podolinsky on the distribution of energy and substance of added value.

Shevchuk elaborates the heritage of the Ukrainian scientific school of physical economy and on the base of it develops a new accounting and reporting paradigm (Shevchuk, 2001, 2013). The author emphasizes the necessity of environmental and economic identification and interpretation of assets as accounting objects. Despite the philosophical and cosmological nature of physical economy, its fundamental scientific provisions can be considered as the basis for the development of economic concepts, theories and paradigms that have significant applied value. Besides the studies of Shevchuk in the field of accounting, this can be confirmed by the outcomes of scientific research in other subject areas of the economy. For example, Hryniv, within the framework of physical economy theoretical principles, has developed the model of monetary relations in the national economy (Hryniv, 2009).

Today the term "physical economy" is often used as a synonym for "energy economics" or "ecological economics". Its main object of study is not only the economic development, but rather the resource dependence and environmental impact of economies. An economy is analyzed as a special kind of living organism evolving under the influence of scientific and technological progress, which is the chief source of increases in the productive power of society (Tennenbaum, 2015).

Overall, the further development of physical economy, according to Shevchuk, may be a way for overcoming the crisis of modern economic thought, triggered by "the domination of political economy over physical; isolation from each other; separate »development«; even parity” (Shevchuk, 2013). Indeed, the current economic doctrine, based on the foundation of political economy, cannot solve the current problems and obstacles for sustainable development and only deepens the environmental crisis. Limited resources and depletion of their reserves only stimulates the growth of their prices and, therefore, intensive exploitation of deposits. At the same time, the society can remain unconscious about the extent of the disaster because the existing system of information support (accounting and reporting) methodologically is not able to alert about it. This is particularly confirmed by the further analysis of non-financial reporting format - Communication on Progress reports to the UN Global Compact, Sustainability reports according to GRI guidelines and others.

Thus, the new accounting and reporting paradigm in the context of relevant representation of social and environmental factors and entities' performance, in view of the above arguments, should take into account scientific provisions of physical economy - the necessity of accounting for and disclosure in general purpose reporting of assets that represent absolute goods and externalities. An important issue is also the choice of accounting measures for these and other social and environmental assets. And although, according to Rudenko, in the absence of measuring instruments to account for expenses and earnings of energy this should be money, but to measure the objects of physical economy by means of the system of monetary relations, built on the principles of political economy, may be meaningless. In our view, it is appropriate to use the natural measures for the representation of social and environmental factors and entities' performance. 


\section{Conclusions}

The current format of company reporting is generally characterized by the low level of relevance and completeness, causing methodological problem of inconsistency between the information needs of users and presented information. On the basis of conducted researches and generalizations it was found that the underlying problem is the obvious imbalance of accounting theory with the stages of economic, technological and informational development of the socio-economic environment. The study proved that the problem of financial reporting inconsistency can be solved only in the framework of new accounting paradigm development, since the explicit anomalies and crises are inherent in the existing.

The results of anomalies and crises of accounting and reporting information analysis have enabled to define that the new accounting paradigm should comply with the following main requirements: explicit positioning of public importance of general purpose of financial reporting (institutional context); complete representation of company's intellectual potential by the system of accounting and financial reporting; consideration of social, environmental and ethical aspects of companies operation as important criteria of their overall effectiveness; consideration of dynamics of an economic development factor in the approaches to accounting objects valuation. It is proved that taking into account these requirements allows elaborating a paradigm, theoretical and methodological foundations which provide a more objective presentation of financial position and performance of corporations in the conditions of post-industrial economy.

\section{References}

Baetge, J., Kirsch, H. J. and Thiele, S. (2014). Bilanzen, 13., überarbeitete Auflage, IDW Verlag, Düsseldorf.

Brooking, A. (1997). Intellectual Capital, International Thomson Business Press, London.

Chaykovskaya, L. A. (2007). Modern Accounting Concepts (Theory and Methodology), Thesis for obtaining $\mathrm{PhD}$ in economic sciences, Plekhanov Russian Academy of Economics, Moscow.

Dyba, B. M. (2009). Intellectual Capital as an Object of Accounting, Finance of Ukraine, No. 2, pp. 118-125.

Edvinsson, L. and Malone, M. S. (1997). Intellectual Capital: Realizing Your Company's True Value by Finding its Hidden Brainpower, Harper Business Press, New York.

Global Compact Network Ukraine. Retrieved January 28, 2017 from: http://www.globalcompact. org.ua/ua/about/inukraine

Global Reporting Initiative. Retrieved January 28, 2017 from: https://www.globalreporting.org/ Pages/default.aspx

Hryniv, L. S. (2009). Development of Physical Economy: New Challenges and Models, [in:] Physical Economy: Research Methodology and Global Mission of Ukraine, Proceedings of the International scientific conference in Kyiv, Ukraine, April 8-10, Kyiv National Economics University, pp. 178-187.

Kravchenko, S. I. and Korneva S. E. (2009). Accounting and Analytical Support of Intellectual Capital Management, Management and Entrepreneurship in Ukraine: Stages of Formation and Development Problems, No. 647, pp. 393-398.

Kuhn, T. S. (1996). The Structure of Scientific Revolutions, $3^{\text {rd }}$ ed., University of Chicago Press, Chicago.

Legenchuk, S. F. (2010). Theory and Methodology of Accounting in the Conditions of Postindustrial Economy, ZDTU, Zhytomyr.
The Paradigms of Accounting and Financial

Reporting 
IJSR 5
Legenchuk, S. F. (2012). Accounting Theoretical Knowledge: From Theory to Metatheory, ZDTU, Zhytomyr.

Lev, B. (2000). New Accounting for the New Economy, Stern School of Business, New York.

Lev, B. (2001). Intangibles: Management, Measurement, and Reporting, Brookings Institution Press, Washington, DC.

Malyuga, N. M. (2005). Accounting in Ukraine: Theory and Methodology, Prospects for Development, ZDTU, Zhytomyr.

Podolinsky, S. A. (2000). Selected Works, compiled by L. Y. Korniychuk, KNEU, Kyiv.

Rudenko, M. (2005). Progress Energy. Essays on the Physical Economy, Jura, Ternopil.

Schumpeter, J. A. [1911] (2008). The Theory of Economic Development: An Inquiry Into Profits, Capital, Credit, Interest, and the Business Cycle, Transaction Publishers, New Brunswick.

Shevchuk, V. O. (2001). Ukrainian Scientific School of Physical Economy: International Dimension and Civilizational Perspective, Jura, Ternopil.

Shevchuk, V. O. (2013). Assets as Objects of Accounting, Control and Analysis: Problems of Environmental and Economic of Identification and Interpretation, Accounting and Finance, Vol. 1 No. 59, pp. 66-73.

Skop, H. I. (2015). Accounting for Intangible Assets: Reflection and Reassessment, Thesis for obtaining PhD, Specialty 08.00.09 Accounting, analysis and audit (by economic activity), Lviv Commercial Academy, Lviv.

Stewart, T. A. (1997). Intellectual Capital: the New Wealth of Organizations, Doubleday, New York.

Tennenbaum, J. (2015). The Physical Economy of National Development. Retrieved January 28, 2017 from: http://www.physicaleconomy.com/node/1

The Conceptual Framework for Financial Reporting (2010), issued by the International Accounting Standards Board (IASB). Retrieved January 28, 2017 from: http://www.ifrs.org/ News/Press-Releases/Documents/ConceptualFW2010vb.pdf

The GRI Sustainability Reporting Guidelines. Retrieved January 28, 2017 from: https://www. globalreporting.org/reporting/g4/Pages/default.aspx

Yaremko, I. J. (2002). Economic Categories in Accounting Methodology, Kamenyar, Lviv.

Zhuk, V. M. (2010). The Use of Institutional Theory in Solving Problems of Accounting, Finance of Ukraine, No. 9, pp. 115-123. 